\title{
Early Childhood Development and Education: Theoretical Convergences and Divergences
}

\author{
Sandra Patricia Varela Londoño ${ }^{1}$, Aurora Bernal Martínez de Soria ${ }^{2} \&$ Sonia Rivas $^{2}$ \\ ${ }^{1}$ Faculty of Education, Universidad de La Sabana, Chía, Colombia \\ ${ }^{2}$ Department of Education and Psychology, Universidad de Navarra, Pamplona, Spain \\ Correspondence: Sandra Patricia Varela Londoño, Campus Puente del Común, Km 7, Autopista Norte de Bogotá, \\ Chía, Cundinamarca, Colombia. E-mail: sandravl@unisabana.edu.co
}

Received: February 2, 2019

Accepted: March 7, 2019

Online Published: June 29, 2019

doi:10.5539/ies.v12n7p1

URL: https://doi.org/10.5539/ies.v12n7p1

\begin{abstract}
This article introduces a theoretical study about convergent and divergent aspects between the concepts of education and early childhood development. This, set up from a social and educational approach, based on a in-depth theoretical review. The beliefs of children's parents and caregivers are highlighted as a significant aspect on children's development; all, considering the practices used for educating them, promoting a holistic child development, or the contrary. These insights make it possible to understand the rationality and applicability of child development and education theories. Hence, we advocate in this manuscript for an interdisciplinary and holistic perspective to approach child development taking into consideration factors and conditions, as well as fusing conceptual frameworks from various disciplines such as psychology, sociology, and philosophy.
\end{abstract}

Keywords: development, education, early childhood, comprehensive care

\section{Introduction}

One of the final goals amidst achieving the Millennium Development Objectives (MDO) to reach the global sustainable development consists on achieving a comprehensive development of early childhood. This purpose is framed between two extremes: eradicate infantile mortality and create the conditions in which the continuous improvement of the youngest population of the nations will be possible. To this aim, the political agendas of the countries state the importance of comprehensive care and education during the first years, providing the conditions needed for quality of life, and education, from pregnancy to six years (UN, 2015).

For UNESCO (2015), early childhood care and education, from a comprehensive view, is considered as the sum of actions related to: satisfying basic needs in education by ensuring quality, opportunity and equality contexts; preserving health from care, nutrition and hygiene, in order to boosting growth; assistance, care, shelter and protection for both women and family, emphasizing the promotion of justice, freedom, and cultural respect; and investing about realities and needs of children and families - of different context- to achieve their development and survival. To reach that, countries design programs, plans and projects from a systemic perspective, through integrated actions and cross-cutting and cross-disciplinary policies aimed at favoring boys' and girls' environments (such as family, school and community). These actions are headed towards fostering the empowerment of population, encouraging education as a basic strategy to promote growth and development in childhood.

In the present paper, the relation between child education and child development is discussed, addressing how the literature has allowed the conceptual overlapping between these terms, without considering that the processes of development and education are both complementary, interdependent (although unique in their nature). Thus, we aim to fill the above gap, describing the convergences and divergences between each other, and highlighting how parents, caregivers and educators can -effectively- generate suitable and holistic conditions that boost child development.

\section{Human Development from a Social Perspective}

Since the $20^{\text {th }}$ century, the United Nations Development Programme (UNDP) starts operating the Human Development Index (HDI), a touchstone to be considered. The dimensions evaluated through it, are: 1) Economic wealth-as part of the Gross Domestic Product (GDP)-understood as the measure of goods and services produced by each society; 2) combined primary, secondary, and tertiary gross enrollment ratio, and; 3) life expectancy 
(UNDP, 2011).

During 1991 and 1992, another indicator was included to measure the human freedom index for assessing the compliance degree of human rights. However, following the suggestion of some governments that did not want their poverty on the subject to be visible, essential aspects of human development such as education are frequently treated in an instrumental way (as if they were a mere capital that entails future revenue).

Thus, Sen (2002) in his work "Libertad y Desarrollo", redefines development in terms of capabilities. He claims that poverty is directly affected by the way development is conceived. He states that poverty cannot be defined just by the income index but through the inability to transform that income into what each person considers necessary and vital for living. In brief, he thinks it is a short a vision that considers that "poor" is just the person whose income is extremely low.

The education dimension of the Human Development Index is made of two measures: mean years of schooling, and expected years of schooling. However, beyond years of schooling, a key issue to broaden the human being skills is education quality. The Programme for International Student Assessment (PISA), of the Organization for Economic Cooperation and Development (OECD), collects comparable data at international level about students' academic achievements. All, looking for comparing, among countries, the average learning scores, the percentage of schools with low performance, and the consistency degree reaching results. In Latin America, for its part, measurements have been mainly developed regarding living conditions and poverty of the population, trying to explain the low scores obtained by the students.

In the case of childhood, two traditional methodological criteria have been followed: poverty measurement by income, and measurement of poverty for unsatisfied basic needs. In particular, UNECLAC and UNICEF, in 2010 and 2012, considering deprivations in terms of methodology and indicators (UNICEF, 2003), made a measurement of child poverty from a human rights approach. Besides, they complemented this evaluation by measuring poverty taking into account the household income, and listing essential rights to achieve children well-being (such as acces to food, drinking water, acceptable sanitary services, health, housing, education and information), applying a territorial approach (Pautassi \& Royo, 2012).

This measurement approach considers as "poor" a child in case of non-compliance with any of their rights, even if is only one. Hence, the report recognizes a conceptual framework with references for countries' development and suggests that comprehensive interventions have to go beyond of basic needs, and to guarantee good nutrition, health and education (Pautassi \& Royo, 2012). Also, it is remarkable that the UNDP evidences evolution of the development category from a sociopolitical perspective. Amidst a myriad of proposals, it seems to be awareness around the direct relation of development and education. In the first Human Development Report (1990) there is a definition of development that is still valid in its essence. It says: "Human development is a process of enlarging people's choices. The most critical ones are to lead a long and healthy life, to be educated and to enjoy a decent standard of living. Additional choices include political freedom, guaranteed human rights and self-respect, and what Adam Smith called the ability to mix with others without being 'ashamed to appear in public"' (PNUS, 1990, p. 33).

It is therefore to create the social conditions in which people can live well, enjoy goods, and act socially; that is, enjoying of their freedoms and capacities (UNDP, 2010). It is considered that people benefit from the obtained assets while contribute to achieve these assets' expansion. According to a diversity of approaches, this concept of development -which responds to the so-called capacity approach-is the one that continues to be at work (UNDP, 2010). People are the beneficiaries and promoters of human development as individuals or social group; and among the groups considered, families are priority. In this way, a greater and better education for people is fundamental, and this start with families.

Education is a dimension of human development, not just a mere instrument to increase human capital or to maintain cultural capital, but to promote social capital. This, taken as social regulations and relationships embodied in social structures of societies that enable people to coordinate their actions to achieve desired goals. People may consider themselves as means of development -because they are able to do development-and as end, in itself, of development. So, in the paradigm of human development, access to knowledge and education is an end in itself (UNDP, 2013).

On the other hand, education can be considered as a means in which human development must "empower" individuals and societies (UNDP, 2010). Empowerment and agency capacity allow the action of individuals and groups, to reach valuable results. It is clear that, without education, that action is not possible; nor is it possible to guarantee the sustainability of people's actions, understood as the way to live the life, aware that everything we do has consequences for the inhabitants of the planet, as well as for the billions that will come in the next centuries 
(UNDP, 2011). Following this logic, human development is sustainable if it is offered "the expansion of the fundamental freedoms of the people of the present, while making reasonable efforts to avoid seriously compromising the freedoms of future generations" (UNDP, 2011, p. 23). In Sen's capacity approach (2002), education -as well as development- has an intrinsic value, a personal instrumental value and an instrumental social value.

Human development, from the sociopolitical perspective, is the development of those societies that make possible each person's growth. From this perspective, intergenerational education is crucial; education confers sustainability on the progress when attaining all development objectives (Bokova, 2014).

Therefore, education has been understood as a dimension of development, and has also been thought of as a dimension of well-being. In this way, the concept of development arises regarding to welfare and quality of life. It is claimed that childhood enjoys life quality if it accesses education, and it is better if it accesses a quality education, although-wrongly-it is usually measured and valued in terms of access to formal education (Andresen, 2011).

\section{Human Development from an Educational Perspective}

From an educational approach, the prevailing focus must be each individual; each person acquires maturity by and develop their potential from the beginning of life. In this sense, the notion of development is parallel to that of growth (emotional, cognitive and physical).

There are as many ways to understand this process as those to understand the human nature. Two different - even incompatible- perspectives stick out when grasping development and, subsequently, the role of education (Egan, 1998). Some have learnt that humans are born as adults in embryo state so just following the nature impulse is enough for them to reach adulthood. Thus, education would be a sort of assistance to avoid obstacles or to encourage changes to follow the biologically determined direction. Hence, the educator's activity is extrinsic, directed towards outside.

A representative of this human growth depiction that has influenced on the so-called naturalistic and libertarian pedagogies is Rousseau. Another one that may be worth to highlight is Piaget, with his psychological theory in which education follows natural development. On the other hand, the evolutionist theory, applied to biology, leads to think that all human beings fulfill the same evolutionary historical stages of development. A similar theory but applied to culture is the one that education is a process of culture transmission in which each individual experiences the civilization stages. Beyond these theories, what remains is the idea of people following a course of changes that can be determined by certain rules, so the educational act implies to follow those rules. Notwithstanding, from a different perspective of the human nature, it is claimed that humans are born with a potential but undetermined natural endowment; especially when it comes to the rational dimension of the human being. For that reason, education departs from the natural capacity, glimpses its purpose but it must guide the development towards an end.

From this view, education is an intrinsic element of development; is the version of the Greek paideia that continues to be until current times. Philosophical interpretations of human development and growth remain valid in the contemporary age, both in formulations of education supported from scientific disciplines-such as Psychology and Health Sciences-, and in pedagogical conceptualizations argued from humanistic disciplines.

From Psychology and Health Sciences, development has been investigated as a process by which the person reaches the functionality of psychological, physical or biological capabilities. Evidences are frequently used to show the different stages of this process; in this way, the description of people's growth according to age-which is very old-has been used as a reference to prescribe how parenting and education should be adapted. The contributions of Psychology and Neuroscience have an impact on the way of understanding development and have an effect on the way the educational agency is presented (Pierce, 2012). The key issue here is to understand the functionality of human faculties, to define their conditions. The extremes between sufficient and maximum functionality become development goals and the way to achieve this, later, turns into the criterion of intervention and educational aid for people.

The development of human capacities to fulfill functions has basically been understood in two ways that, over time, have approached each other (Álvarez \& Del Río, 2013). On the one hand, from the theory of genetic functionalism it is thought that development, basically, depends on the program inherited by each individual and the environmental conditions that allow his evolution. Thus, parenting and education become the environmental supports for individuals to grow in basic skills, and even in the superior or complex ones. From this viewpoint, authors tend to think that a series of transformations take place almost irreversibly, as if each individual growing up 
could be a system that follows a process of change that advances by itself with some external help. However, this dynamism does not seem to be fulfilled when the rational dimension of development linked with the influence of social, cultural and historical contexts. In fact, by including the rational dimension, we overcome the time of change, connecting past, present and future which interfering the process (Lyra \& Valsiner, 2012).

The evidence about whether children develop themselves out of culture, raised a theory complementary to that of genetic functionalism, called mediated functionalism. In this way, support received by children from other people cannot be reduced to a stimulation or guide of a process whose fundamental weight is the intrinsic dynamism of the natural or biological potentiality. Human development is also cultural, and education encourages it by promoting the dynamism of psychological functions (especially, those that have to do with rationality). Each boy and girl incorporates cultural advances due to education mediation, and education is no longer seen as a means of transmitting knowledge, but rather as a means that fosters situations in which children act and develop their abilities (Rodríguez-Burgos, Rosero-Burbano, Rodríguez-Castro, Díaz-Posada, \& Mojica, 2014).

These concepts of development are linked to learning theories, better known from the contributions of psychology and neuroscience, in which development and learning are interrelationated. Thus, development involves updating functions by awakening physical, moral, social, emotional, and other skills; and well-being is also being achieved, updating the potential level of a person in different social levels.

The appropriate intervention for this, impulse that is assimilated to education, assumes to standardize the development process by solving the difficulties and risks by adopting preventive measures (Ferrer-Wreder, 2014). However, part of the psychology applied to education, and linked to neuroscience, pays more attention to the biological functionality in the learning process; while another part heads towards the social impact, influencing the trends in the way educators conceive and promote children's development (Smeyers \& Depapep, 2013).

In Colombia, a document was made to assess children's development through skills understood as the general abilities that allow identifying those "be, know, do" that children reveal throughout their development. As it is known, competencies are not directly observed but through performances and actions performed by children in everyday or structured situations. Competence is characterized because it mobilizes and enhances the knowledge emerged from a specific situation, towards different situations, and is flexible in nature (MEN Colombia, 2010). Another way of observing competencies is through reorganizing experiences that represent crossroads in development. Competencies are considered as the result of integrating previous skills that allow children to access new "doings and knowledge" (and enable them to move towards more complex ways of thinking). This requires that children work with their cognitive, affective and social resources, which is better if occurs in significant spaces, in daily experiences on which children are invited to reflect and solve problematic situations (with opportunities to advance in their development). Subsequently, that child development occurs depends on educational intention, learning moments well-designed, integrating expressive and communicative languages, and significant interactions that educators and adults maintain with the child (Díaz-Posada \& Rodríguez-Burgos, 2018).

For example, during the interaction between the baby and his mother or primary caregiver, essential functions may be performed such as interest in reality, motivation, focal attention, exploration, thinking, etc. In consequence, it is important to keep in mind that the exchange between educators and children must be mediated by emotion, intuition, intentionality, and a large of sensitivity.

\section{Education from a Social Perspective}

In the present study, education from a social approach is understood as the process of cultural, moral and behavioral bonding and awareness in which new generations assimilate and learn knowledge, rules of conduct, ways of being, ways of seeing the world and creating knowledge.

The primary social areas of education are family and school. Currently, the education that emerges from the family is "preferably transmitted by example" and includes, as constitutive factors, "love, authority, self-esteem, acceptance, intensity in the service and time to be together" (Parada, 2010, p. 31). This concept of family education, which is linked to people's lifestyle, and where the family is known as a primary socialization area, departs - precisely- from what is defined as a family; even more when, according to the Universal Declaration of Human Rights in 1948, it is considered as "the natural and fundamental element of society" (UN, 1948, p. 5).

García et al. (2001) defines family as "the first context of learning social rules and, therefore, the first socializing agent of the values acquired by its members" (p. 204). Another definition is provided by Rodrigo and Palacios (1998), who describe it as the group of people who share an enduring life project, in which strong feelings of belonging are generated, and there is a mutual personal commitment among members, establishing intense 
relationships (of intimacy, reciprocity and dependence). Is in the home where embracement, development and emotional balance are promoted; where the first learning occur (Rodríguez et al., 2009). The key issue here lays on how to assist and care for children until they reach adulthood. Sometimes education is considered as a cumulative process in continuation with parenting, and is not considered a perspective of cooperation.

In this case, upbringing means the activity of paying attention to nutrition, hygiene and psychological stimulation, especially in early childhood, when upbringing is added to breastfeeding (for example). The meaning given to education is to feed the rational -cognitive and volitional- capacity, the social and moral capacity; that is, the human not strictly biological dimensions. Rising is linked to corporeal, while educating is joined to what is psychic, rational and spiritual. Upbringing is often seen as the care that provides children's conditions of well-being, and researchers equate education and socialization (Rodríguez et al., 2009).

The research confirms that: "the most effective programs for the well-being and development of the child are those that include nutrition, health, care and education more than those that only address one aspect" (Burnet, 2007, p. 5). Achieving the articulation of the different sectors and seeking inclusive care is one of the main challenges when society works for a comprehensive care and education of children.

Sometimes, education appears as a parenting element that may be defined as a multidirectional process through which knowledge, values, customs and ways of acting are transmitted. Parada (2010) translates it as "caring, loving, nurturing, guiding" and points out that "the objective of family education consists on shaping honest, authentic people, fully developed in their personal potentialities, balanced individuals with a scale of values to which they adjust their behavior, who are coherent with themselves and socially committed" (Parada, 2010, p. 29).

\section{Education from a Pedagogical Perspective}

The pedagogical approach, that is, the vision from the applied sciences to education, allows researchers to understand if the meaning of education has to do with an impulse for the development of people (or it could refer to some other purpose). "Early childhood care and education aims to support survival, growth, development and learning of the child which includes taking care of their health, nutrition, hygiene, as well as their cognitive, social, physical and emotional development from his birth until his enrollment into the primary school, in formal, non-formal and informal contexts" (Burnet, 2007, p. 3).

Why and what for are the processes of parenting and are questions that depend on the ideas that a society, a culture, or the responsible for education have about childhood (Main, 2012). The story about the conception of childhood in the West, and about the human being in general, highlights motives and purposes supported by the processes of upbringing and education: caring, empowering, correcting, preventing, achieving. The actions that integrate education, those who educate and those who are educated, are undertaken with a purpose. The educational action has to involve intentions, goals and ends; remembering that everything is mediated by people, cultures, societies, and transformations. Education is not spontaneous, in the major of cases, and could not be attained only through the laws dictated taking into account the typical dynamics of growth and development of people. For this reason, it is not enough to define education as a boost to the development of people's capacities.

Hence, there are convergences in similar issues, as if education is associated with learning, with the impulse of learning. Curren (2007) said that: "Education is a set of somehow systematic practices of supervising and guiding the people's activities along the road to promote valuable ways of learning and development" (p. 3). Education is not reduced to arousing learning. So, it is important to know, not only that the person learns, but what he / she is capable to do and, at the bottom, to choose with what he / she learns. Also, the person can create new contents and products; and this is the way for expanding social and cultural development.

The difference between human learning and animal learning is focused in the rational capacities and it entails that education needs aims to boost and assist learning. The educational purpose is the promotion of the human being, and the opening to its purpose always indicates a reference of value and regulations. The person is valuable in himself; however, his excellence is best shown if he is educated. The capacities that the person deploys are valuable in themselves; means the possibility be to enjoy health, to obtain a job, to contribute to social cohesion, to collaborate with human development. If education is considered or focused as a development impulse, and we are keen on a naturalistic vision, we only notice from people their functional character (Carr, 2005).

Now, to educate and to be educated is needed to consider what is desirable for people: Educate for well-being? Educate for happiness? Educate for freedom? Educate for human development? Educate to socially fit, to work, to do...? Educate to reach personal fulfillment? Educate for equity? The answers suppose an assessment of what human is, and a conception of its deployment. Of course, to raise some answers, it is not enough with the knowledge that sciences provide about human development (Bagattini, 2014). Sciences describe certain aspects, 
but it is people who decide what to do, what belief, and what apply.

For that motif, it may be more appropriate to make explicit a definition of education that integrates a humanistic with a scientific conceptualization, because educating is: "assisting development until it reaches completeness, stimulating, moving the disposition to do the best [...]; to 'take out', 'extract', 'advance', 'raise', express the diverse operational dimensions enclosed in education" (De Ruyter, 2012, p. 30).

In these senses, the action of the educator is not about 'putting in' but about 'taking out' / 'extracting', to make it meaningful. It implies an improvement for those who are educated; 'to advance' / 'to elevate', in an orientation of improvement, granting the value of immanence (Altarejos, 2003). This aspiration has been criticized as harmful perfectionism, potential "stressor" of learners and educators when they are asked to reach the maximum before unveiling an ability or talent. However, seeking perfection does not have to result in perfectionism. It depends on how are given the purposes. An education oriented to perfectionism ends up being an instrumentalization of people, in which the concern is people's productivity more than people.

De Ruyter's proposal is interesting because it broadens the educational purpose by arguing that through education is possible to look for an optimal development; complete goods, objectives for all people in harmony with the goods of and for a person. The word 'optimal' announces balance, realism, a harmony among abilities, possibilities and aspirations, reaching a complete well-being. Optimal development is instrumental for people's flourishing. They should star what they want to be, and include others; it is about empowering, not the talent of some, but everybody's talents. Seeking those objective goods, of all, becomes a normative principle. Pursuing ideals makes people grow, and it is a healthy process if they are self-oriented rather than the result of others' impositions. This idea is also approached by Nussbaum (2011) in the argument of human development defined as capabilities' creation, from a ten capabilities' list-that integrate human development-, among there is the next one: "Being able to form a conception of the good and to engage in critical reflection about the planning of one's life" (Nussbaum, 2011, p. 54).

Respect to that, research reveals how rules of conduct and family life practices are very important for the education of children, and one of the most solid ideas that brings these practices together is what will this child like (Perinat, 2012). Consequently, the design of an education program should be a delicate fit between expectations and interests of families, the environment in which they live, ideas about the world, values, etc. Education is a cultural practice-primarily-because its main purpose is to make sense in the world and about the world, and the secondary, subordinated to the first, is to help work in the world to make that sense. To educate is necessary to think about what could should the base, how we are, and how we can be. This reality suggests the interest of understanding the beliefs of parents and other educators towards parenting and education, not just about how they should be carried out but also regarding what they expect from these processes (or even what they propose).

Likewise, the value of parents' beliefs leads to glimpse the importance of this type of reflections in family education programs, for which it is reasonable and convenient, not only to transmit strategies and teach competences of care and assistance to early childhood. On the contrary, in order to promote the practical rationality of those responsible for each family, inviting them to decide how they can help children to lead their lives. In addition, parents will also think about what are the best ways to conduct their children's development and to be consistent in regard to what they live and what they educate for. As a result, parents' beliefs about parenting and education meaning and purpose -and their relationship to child development-impact the way children's education and care are addressed and executed.

For the research carried out, belief is understood as those explanations, for a justification, that is provided by parents/teachers regarding the way in which they guide the children (Izzedin \& Pachajoa, 2009). Likewise, children development has to be understood as process in which all areas advance simultaneously, in a continuous process of development and improvement throughout life. There, family and caregivers are linked as guarantors that favor opportunities and that fully embrace the person (Bernal, Rodríguez, Altarejos, Naval, \& Castillo, 2005). On the other hand, the practices are conceived as those intentional behaviors that are regulated and executed by adults to guarantee the survival of the child, promote their development and acquisition of knowledge that allows them to be in relation with a context (Aguirre \& Durán, 2000).

There are convergences between the beliefs and practices of parents and caregivers when facing the importance of promoting child development. This, through actions, improves from their knowledge about the daily life situations (and trying that children face the error in a proper way). It is there where the guidelines parents establish within their families are understood as the model that directs, guides and orients. Practice is the behavior intended and regulated by adults for children's education; and beliefs are the explanations that they give for their actions'. 


\section{Conclusions}

In short, convergent and divergent aspects of the concepts 'education' and 'development' in early childhood, according to what theory proposes, are discussed. This, showing that intentional education that makes sense in people-parents and caregivers-leads to empower children's development and it, by itself, promotes social transformations. This affirmation demands expanding social capital, in terms of greater human and cultural opportunities. Without doubt, parents and caregivers are the people who most contribute to the development of boys and girls.

An important convergence is that the two concepts-education and development-are linked to growth, which causes that semantically these are used as synonyms or complements in theoretical frameworks. For parents and caregivers, inclusive development of children could be understood as a totalizing concept, due to its comprehensive condition, which includes all dimensions of development. Also, to be enhanced, child development requires and special assistance in the first years, taking care of children from gestation. Children, although fomenting their independence, require aids, accompaniment, good example, and encouragement through an education of quality in and from home. All these actions seek to promote the human being deployment and potentiality in the first and most determinant life period: early childhood. Besides, it is important to respond to parent's beliefs through actions that they can perform with their children. Everything, overcoming daily difficulties as: lack of time, lack of resources, demanding jobs, home conditions, among others. Parents and caregivers need to emphasize the importance of modeling good behaviors and understand aspects related to learning in the first years.

Also, parenting needs to be a point of reference as a part of education, considering the needs of each child and the creation of stimulating contexts; scenarios that allow the construction of positive and healthy interactions, that facilitates to recognize common goods. Therefore, parenting is a means to contribute to children's development and transcends the welfare dependent approach; though it is not so clear how early childhood education also serves this purpose. This divergence is produced by the different ways of understanding what development is and what education is.

The challenge that arises is primarily for families, as basic and fundamental group, to be more engaged to the State programs in which they are seen as comprehensive persons (rather than a sum of services in which assistance is blurred and the importance of being a primary socializer and first educational field for children in early childhood). In this aspect divergences appear regarding what the theory raises on the articulated and preponderant work of the family.

On the other hand, convergences are evidenced between what was found in theoretical approaches reviewed in regard to topics such as: development deploys capabilities and requires some training to be effective and to fulfill educational functions. It is clear that understanding, conceptualization, strategies, learning, good practices, discursive clarity on education, and strategies for development are mediated by parents' and caregivers' education level and cultural influences. So, to conclude, and to introduce possible issues that can be considered from empirical research, the next are some question considered important: a) Do the parents (or other responsible family members of the children) believe that contributing to the development of children is to contribute to the development of society -promoting the capability of social agency-? Do they have the expectation that by raising and educating children, the sustainable development of the future society is prepared? b) Do parents/teachers believe that family education is a development opportunity? c) Do parents believe that promoting development is to continue the natural growth of children? Do they think that by education they bring children more than nature gives them? d) Do parents believe that by raising -feeding, nourishing, and taking care of hygiene- they can also educate -impart knowledge, values, habits, and abilities-? e) Do parents/teachers believe that education is useful for children to grow to their completeness (full and complete development) or do they only appreciate the instrumental value of education (development of the child's functional dimensions)?

\section{References}

Aguirre, E., \& Durán, E. (2000). Socialización: prácticas de crianza y cuidado de la salud. Bogotá, D.C.: Centro de Estudios Sociales - Universidad Nacional de Colombia. https://doi.org/10.18273/revsal.v51n1-2019005

Altarejos, F. (2000). Filosofía de la Educación. Pamplona: Ediciones Eunsa.

Álvarez, A., \& Del Río, P. (2013). El papel de la educación en el desarrollo: De la escuela a la cultura. Cultura y Educación, 25(2), 137-151. https://doi.org/10.1174/113564013806631309

Andersen, S. (2011). Educational science and child well-being. In A. Ben-Arieh (Ed.), Handbook of child well-being: Theories, methods and policies in global perspective (pp. 249-278). Dorchecht: Springer Netherlands. https://doi.org/10.1007/978-90-481-9063-8_11 
Bagattini, A. (2014). Child, well-being. A philosophical perspective. In A. Ben-Arieh (Ed.), Handbook of child well-being: Theories, methods and policies in global perspective (pp. 163-186). Dorchecht: Springer Netherlands. https://doi.org/10.1007/978-90-481-9063-8_8

Bernal, A., Rodríguez, A., Altarejos, F., Naval, C., \& Castillo, G. (2005). La familia como ámbito educativo. Pamplona: Rialp.

Bokova, I. (2014). Presentación. In P. Rose (Ed.), Informe del seguimiento de Educación Para Todos en el mundo 2014: Enseñanza y aprendizaje, lograr la calidad para todos (pp. 159-166). París: Unesco. $\mathrm{https://doi.org/10.17141/mundosplurales.1.2015.1915}$

Burnett, N. (2007). Informe del seguimiento de Educación Para Todos en el mundo 2007: Bases sólidas. Atención y educación de la primera infancia. París: Unesco. https://doi.org/10.1016/s0185-2698(13)71826-9

Carr, D. (2005). El sentido de la educación. Una introducción a la filosofía y teoría de la educación y la enseñanza. Barcelona: Graó. https://doi.org/10.17227/01203916.7576

CONPES 109. (2006). Política pública nacional de primera infancia: Colombia por la primera infancia. Bogotá, D.C.: Congreso de Colombia, Departamento Nacional de Planeación. https://doi.org/10.18273/revbol.v39n2-2017004

Curren, R. (2012). Philosophy of education. An anthology. Oxford: Blackwell.

De Ruyter, D. J. (2012). On optimal development and becoming on optimizer. Journal of Philosophy of Education, 46(1), 25-41.

Díaz-Posada, L. E., \& Rodríguez-Burgos, L. P. (2018). New theoretical and methodological ways in the study of "affectivating". In C. Cornejo, Marsico, G., \& J. Valsiner (Eds.), I activate you to affect me (Vol. 2, Serie Annals of Cultural Psychology) (pp. 275-281). Charlotte, NC: Information Age Publishing.

Egan, K. (1998). Conceptions of development in education. Philosophy of Education, 53-61.

Ferrer-Wreder, L. (2014). Advancing child and adolescent well-being through positive youth development and prevention program. In A. Ben-Arieh (Ed.), Handbook of child well-being: Theories, methods and policies in global perspective (pp. 3025-3041). Dorchecht: Springer Netherlands. https://doi.org/10.1007/978-90-481-9063-8_164

García, M., Ramírez, G., \& Lima, A. (2001). La construcción de valores en la familia. In M. Rodrigo, \& J. Palacios (Coords.), Familia y desarrollo humano. Madrid: Alianza. https://doi.org/10.4272/978-8497-45-254-0.ch4

Hoshmand, L. T., \& Polkinghorne, D. E. (1992). Redefining the science-practice relationship and professional training. American Psychologist, 47(1), 55-66. https://doi.org/10.1037//0003-066x.47.1.55

Izzedin, R., \& Pachajoa, A. (2009). Pautas, prácticas y creencias acerca de crianza. Ayer y hoy. Liberabit, 15(2), 109-115.

Lyra, M. C. D., \& Valsiner, J. (2012). Historicity in development: Abbreviation in mother-infant communications. Infancia y Aprendizaje, 34(2), 195-203. https://doi.org/10.1174/021037011795377638

Main, S. (2012). 'The Other Half' of Education: Unconscious education of children. Educational Philosophy and Theory, 44(1), 82-95. https://doi.org/10.1111/j.1469-5812.2010.00643.x

MEN Colombia. (2010). Educación para la primera infancia-Antecedentes. Bogotá, D.C.: Author.

Nusbaum, M. (2011). Crear capacidades: Propuesta para el desarrollo humano. Barcelona: Paidós.

ONU. (1948). Declaración Universal de Derechos Humanos. Retrieved from https://bit.ly/1hHDu9u

ONU. (2015). Objetivos de desarrollo del milenio. Informe de 2015. New York, NY: Author. Retrieved from https://bit.ly/2LxXphT

Parada, J. L. (2010). La educación familiar en la familia del pasado, presente y futuro. Educación Siglo XXI, 28(1), 17-40.

Pautassi, L., \& Royo, L. (2012). Enfoque de derechos en las políticas de infancia. Indicadores para su medición. Santiago de Chile: CEPAL, UNICEF. Retrieved from https://bit.ly/2I08YHu

Perinat, A. (2012). Cultura, educación y desarrollo humano en América Latina. Cultura y Educación, 24(1), 11-124. https://doi.org/10.1174/113564012799740803 
Pierce, C. (2012). The promissory future(s) of education: Rethinking scientific literacy in the era of biocapitalism. Educational Philosophy and Theory, 44(1), 721-745. https://doi.org/10.1111/j.1469-5812.2010.00736.x

PNUD. (1990). Informe sobre desarrollo humano: Concepto y medición del desarrollo humano. Oxford, UK: Author. https://doi.org/10.18356/8ab1e66e-es

PNUD. (2010). Informe sobre el desarrollo humano 2010: La verdadera riqueza de las naciones. Caminos al desarrollo humano. México, D.F.: Ediciones Mundi Prensa. https://doi.org/10.21678/apuntes.39.450

PNUD. (2011). Informe sobre desarrollo humano: Sostenibilidad y equidad - Un mejor futuro para todos. Madrid: Mundi Prensa Libros. Retrieved from https://bit.ly/2dNz1sl

PNUD. (2013). Informe sobre desarrollo humano: El ascenso del sur-Progreso humano en un mundo diverso. Madrid: Mundi-Prensa. https://doi.org/10.18356/c1568445-es

Ramaekers, S., \& Suissa, J. (2012). What all parents need to know? Exploring the hidden normativity of the language of developmental psychology in parenting. Journal of Philosophy of Education, 46(3), 352-369. https://doi.org/10.1111/j.1467-9752.2012.00866.x

Rodríguez, M. C., Peña, J. V., \& Torío, S. (2009). La experiencia de la paternidad y la maternidad: Análisis del discurso de las creencias sobre la crianza y el cuidado infantil. Infancia y Aprendizaje, 32(1), 81-95. https://doi.org/10.1174/021037009787138248

Rodríguez, X., Araque, F., \& Salazar, E. (2009). Nociones de familia en el discurso de profesionales de trabajo social en espacios escolares. Cuadernos de Trabajo Social, 16, 91-100. https://doi.org/10.14198/altern2009.16.7

Rodríguez-Burgos, L. P., Rosero-Burbano, R. F., Rodríguez-Castro, J., Díaz-Posada, L. E., \& Mojica, A. M. (2014). Understanding cognitive planning from an idiographic perspective. In Y. Omi, L. P. Rodríguez-Burgos, \& M. C. Peralta-Gómez (Eds.), Lives and relationships: Culture in transitions between social roles. Charlotte, NC: Information Age Publishing.

Sen, A. (2002). Closing the gap. Access, inclusion and achievement. Discurso presentado en la $15^{\circ}$ Conferencia de Ministros de Educación de la Commonwealth. Edimburgo. Retrieved from https://bit.ly/2Q0COBh

Smeyers, P., \& Depaepe, M. (2013). Making sense of the attraction of psychology: On the strengths and weaknesses for education and educational research. In P. Smeyers, \& M. Depaepe (Eds.), Educational research: The attraction of psychology (pp. 1-10). London, UK: Springer. https://doi.org/10.1007/978-94-007-5038-8_1

Tamayo, M. (2002). El proceso de la investigación cientifica (4th ed.). México, D.F. Noriega Editores.

UNICEF. (2003). Para la vida. Nueva York, NY: Retrieved from https://uni.cf/2PYOEvC

\section{Acknowledgments}

The present study arises from a research conducted for a doctorate thesis titled Significance of Family Education in Children Development: Study of a Colombian Population, developed at the Universidad of Navarra (Spain). It additionally was funded by Universidad de La Sabana (Colombia), through the Professors' Special Patrimony Fund.

\section{Copyrights}

Copyright for this article is retained by the author(s), with first publication rights granted to the journal.

This is an open-access article distributed under the terms and conditions of the Creative Commons Attribution license (http://creativecommons.org/licenses/by/4.0/). 